\title{
DIVE SITE ATTRACTIVENESS INDEX (DSAI) AS AN INNOVATION IN SCUBA DIVING TOURISM: A CASE OF PERHENTIAN ISLANDS
}

\author{
Nurul Haqimin Mohd Salleh${ }^{1}$, Norlinda Mohd Rozar², Noor Apandi Osnin ${ }^{3}$, Mohd Safuan Che Din ${ }^{4}$, \\ Nurul Asmidah Mohd Azli ${ }^{5}$ \& Sharifah Noor Ridzwan Syed Muhammad ${ }^{6}$ \\ 1,2,3Faculty of Maritime Studies, Universiti Malaysia Terengganu \\ ${ }^{4}$ Institute of Oceanography and Environment, Universiti Malaysia Terengganu \\ ${ }^{5}$ Schenker Logistics (M) Sdn. Bhd., 81560 Gelang Patah, Malaysia \\ ${ }^{6}$ Sea Voice Divers, 22300 Besut, Malaysia \\ (haqimin@umt.edu.my, norlinda.rozar@umt.edu.my, apandi@umt.edu.my, mscd87@gmail.com, \\ asmidahazli89@gmail.com, sharifahnr.sm@gmail.com)
}

\begin{abstract}
Dive sites which are home to various forms of marine life, unique structures and corals have become the main attraction for scuba divers. Divers normally choose the most attractive diving sites by visiting dive centers or getting referrals from other divers. However, there is problem in conventional subjective judgments where no standard measures have been considered. As a result, the judgments on dive site attractiveness may satisfy some divers but not others. To avoid these uncertainties, this research innovatively developed the world's first index model for the attractiveness a dive site. Eight factors have been carefully selected, namely visibility, current stability, uniqueness of underwater scenery, coral health, the immensity of the coral reef, diversity and density of marine life. Then, these identified factors were ranked and assessed by using an Analytical Hierarchy Process (AHP) and Evidential Reasoning (ER). Finally, all dive sites are indexed so it can be compared with others for better decision-making. To test the applicability of this proposed model, 22 dive sites in Perhentian Island were successfully assessed, indexed, and mapped. Terumbu Tiga (T3), Sail Rock and Tokong Laut were indexed as the top three dive sites in Perhentian Islands. The results also showed that the most profound factor that determined the attractiveness of a dive site was the diversity of its marine life followed by the diversity of its coral species, and the uniqueness of its underwater scenery. Practically, this model can be applied and widely used for indexing all dive sites in the world based on decision-makers' preferences. It is expected that this index model will benefit divers, dive centers, marine parks, and related agencies by providing a new information that can be used in marine tourism.
\end{abstract}

KEYWORDS: Scuba diving, marine tourism, Dive Site Attractiveness Index (DSAI), Perhentian Islands, Analytical Hierarchy Process (AHP), Evidential Reasoning (ER)

\section{PURPOSE AND BACKGROUND}

The problem of assessing attractiveness for a dive site which is based solely on assumptions, rumors, beliefs, and opinions from different human views. This effects the correctness or inaccuracy of the statements. This is because subjective views occur through past experiences, perceptions, and desires. To avoid these uncertainties, this research develops a novel model by indexing the attractiveness of dive site based on a mathematical calculation. Firstly, dive site attractiveness features are identified. Eight factors were considered namely visibility, current stability, uniqueness of underwater scenery, coral health, immensity of coral reef, diversity and density of marine life at the dive site. Then, these identified factors are ranked 
and assessed by using Analytical Hierarchy Process (AHP) and Evidential Reasoning (ER). Finally, each dive sites will be indexed so it can be compared with other dive sites for better benchmarking (i.e., visual maps).

\section{METHODOLOGY}

For the purposes of this research paper, a Dive Site Attractiveness Index (DSAI) a tool used to measure the attractiveness of a dive site was used. There are two mathematical methods used in this index methodology which are the Analytical Hierarchy Process (AHP) and the Evidential Reasoning (ER) methods. Saaty (1980) introduced AHP as an efficient tool in dealing with complex decision making and would aid the decision maker in setting priorities and making the best decision. While the ER method was employed for the synthesis of all subsets after all key features at dive site had been assessed. For the purpose developing the dive site attractiveness indexing process, a flow of the proposed methodology consisting of seven steps is illustrated in sequential order.

\section{FINDINGS}

Based on the AHP, the diversity of marine life has been judged to be the prime feature for dive site attractiveness with the highest value of 0.1862 , followed by the diversity of coral species (0.1696), uniqueness of underwater scenery (0.1551), visibility (0.1300), immensity of coral reef (0.1048), density of marine life (0.1044), coral healthy (0.0802) and current stability (0.0697). The results show that based on 15 experts' judgments, dive sites with a high diversity of marine life and coral species have become the most preferred dive spots while current stability was the least significant feature when choosing the best dive sites. The DSAI assessment of the test location, revealed that the most attractive dive site in Perhentian Island is Terumbu Tiga (T3), which ultimately become the top dive site when compared to 21 others. Terumbu Tiga is also known as "The Three Brothers, located at quite a distance from the main island resulting in infrequent dive visits. The visibility is usually very clear (i.e., the DSAI assessed visibility at Terumbu Tiga as 0.877). The diversity of marine life at Terumbu Tiga is also very high with significant concentrations of reef fish, pelagic fish, and blacktip sharks.

As a result, of the DSAI, the diversity and density of marine life at Terumbu Tiga have been assessed as a perfect 1. Moreover, Terumbu Tiga has also scored perfectly for coral health (0.9466), diversity of species (1) and coral reef immensity (0.9466). The other special feature of Terumbu Tiga the uniqueness of underwater scenery which showcases several small caves, perfect for underwater photography with very clear visibility. Some experts shred their views that this dive site is also great for cave diving in Perhentian Island as the location itself has many rocks. Of the 21 other dive spots assessed, the index has ranked the Maritime Wreck as the most least attractive dive spot in Perhentian Island with the value of 0.1991, it scored 0 for both coral diversity, marine life density and diversity with the only attraction of this dive spot being a single shipwreck.

\section{CONCLUSION}

It is worth mentioning that marine tourism has contributed a substantial amount of income to the national economy, especially in Malaysia. Being cognisant of this significant impact on the economy should make improvements of social and practical innovation a necessity. This paper innovatively proposed an index model for the attractiveness a dive site. Eight key features have been carefully selected which are visibility, current stability, uniqueness of underwater scenery, coral healthy, and diversity of marine life, immensity 
of coral reef, diversity of marine life and density of marine life. All the dive sites were indexed so it could be compared with others for better decision-making.

Practically, this model can be applied and widely used for indexing all dive sites in the world for better decision making. It is noteworthy to mention that this proposed model can be adjusted or modified based on a decision makers' preferences. It is expected that this index model will benefit divers, dive centers, marine parks, and other related agencies by providing new information that can be used to improve diving tourism. In future, the current research will be continued by looking at the decision-making model for selecting which dive sites need a "resting period" after being "overpopulated" by divers to allow for the natural restoration to occur.

\section{CONTRIBUTION/PRACTICAL IMPLICATIONS}

Looking on the practicability of the proposed DSAI model, this research is expected to contribute to diving tourism in many ways. First, by using the proposed model, all dive sites around the world can be indexed so each dive sites attractiveness can be presented in an index number.

Consequently, a clear decision can be made without the need for subjective judgement to be made under uncertain and ambiguous conditions. Owing to the concern of its commercial practicability, the proposed model has been successfully copyrighted under Perbadanan Harta Intelek Malaysia in 2020.

Additionally, as most of dive centers and marine tourism information centers display the available dive sites in the area with traditional maps, the current research can improve the map by adding the new information on the attractiveness of the dive sites on display. As a result, Figure 5 illustrates the novel "Map of Dive Site Risk \& Attractiveness Index" in Perhentian Island resulted from the test case conducted in Section 5 while "Dive Site Risk Index" can be referred to Anuar et al. (2020). It is noteworthy to mention that this map under the application process for a "trademark" which can be commercialised and then used on Perhentian Island in the future.

\section{ACKNOWLEDGEMENTS}

This research was conducted under the Knowledge and Technology Assimilation Grant Schemes (KTAGS) (UMT/PIJI/2-2/25/15/JLD1(63)) and using the research facilities of the Universiti Malaysia Terengganu (UMT).

\section{REFERENCES}

Anuar, M. A. H., Salleh, N. H. M., \& Jeevan, J. (2020). Developing dive site risk assessment model (DSRAM) to enhance tourism safety and sustainability in Perhentian Island. J Sustain Sci Manag, 15(1), 125-135.

Saaty, T. L. (1980). The Analytic Hierarchy Process. New York: McGraw-Hill.

Uyarra, M. C., Watkinson, A. R., \& Cote, I. M. (2009). Managing dive tourism for the sustainable use of coral reefs: Validating diver perceptions of attractive site features. Environmental Management, 43(1), $1-16$. 